\title{
IMPORTANCE OF ANGIOGRAPHIC STUDY IN PREOPERATIVE PLANNING OF CONJOINED TWINS: CASE REPORT
}

Francisco Cesar Carnevale ${ }^{\mathrm{a}}$, Marcus Vinicius Borges ${ }^{\mathrm{a}}$, Breno Boueri Affonso ${ }^{\mathrm{a}}$, Ricardo Augusto de Paula Pinto ${ }^{\mathrm{a}}$, Uenis Tannuri ${ }^{\mathrm{b}}$, and João Gilberto Maksoud ${ }^{\mathrm{b}}$

The occurrence of conjoined twins is rare. Its actual prevalence is unknown, but it is estimated to range from $1: 50,000$ to $1: 200,000^{1-4}$ with a higher level of incidence in Southwest Asia and Africa where an occurrence of $1: 14,000$ to $1: 25,000^{5}$ is observed, with a female predominance ratio of $3: 1 .^{4}$

Its etiology is unknown, but an incomplete division of the zygote between $13^{\text {th }}$ and $15^{\text {th }}$ days after fertilization probably occurs. ${ }^{3,5-7}$ About $40 \%$ to $60 \%$ of the conjoined twins are born alive, and almost $35 \%$ of these live-born neonates die within 24 hours. ${ }^{4}$

Usually, the surgery for separation of twins is not performed soon after the birth unless some anomaly puts in risk the life of one or of both children. Therefore, in most cases it is recommended to wait for the twins to grow, making the operative procedure technically easier.

The importance of a detailed preoperative assessment of the various organs leading to precise anatomical knowledge and therefore to a comprehensive preoperative planning is quite well known. Nevertheless, there is not an established algorithm for these evaluations that provides for the diversified anatomical variations existing from case to case.

With the development of noninvasive imaging methods, there was a decrease in the use of angiography as a preoperative assessment method in the hepatic resections. Most of the reports found in the literature emphasize the use of computed tomography (CT) scanning in preoperative planning, attributing to the other diagnostic methods a secondary role with succinct descriptions.

The aim of this article is to present a case of ischiopagus twins whose surgical separation without the sacrifice of one of them seemed impracticable after helical CT and

a Department of Radiology, Children's Institute, Hospital das Clínicas, São Paulo University Medical School - São Paulo/SP, Brazil.

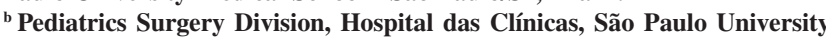
Medical School - São Paulo/SP, Brazil.

Email: fcarnevale@uol.com.br ultrasonography (US) evaluations and whose successful surgical separation became possible after a more detailed angiographic vascular study.

\section{CASE REPORT}

Female ischiopagus tripus twins, of 15 months of age, were evaluated for the possibility of separation. They were joined below the xiphoid process at an angle of approximately 90 degrees. The twins shared a single pelvis, and each child exhibited a normal anterior lower limb and a conjugated posterior lower one. One of the twins was visibly bigger than the other.

The preoperative radiological evaluation showed the following:

A - Bone structure - plain radiography and helical CT scan:

Completely separated vertebral columns and sacra, without visible alterations. The region anterior to the pelvic bones formed a single ring, with a normal pubic symphysis and 2 acetabula articulating the normal lower limbs. In the posterior region of the pelvis, the iliac bones articulated an atrophied limb with a single femur and tibia and a bifid foot.

B - Cardiovascular system - plain radiography, echocardiogram and helical CT:

The larger child presented the heart directed towards the left and the aortic arch coursing to the right, with an existing inferior vena cava (IVC) and agenesis of the superior vena cava (SVC).

The smaller child exhibited the heart directed to the right and the aortic arch turned to the left with IVC agenesis.

C - Urogenital system - Intravenous Pyelogram and helical CT:

The bigger child presented 2 kidneys ( 1 of them with ureteral duplicity and 1 of these ureters draining into the bladder of her sister), a bladder, and urethra. The smaller 
twin had only 1 kidney and 2 ureters (with 1 of them draining into the sister's bladder), a bladder and urethra. Each infant presented independent vaginal vestibule, vagina, and uterus.

D- Gastrointestinal system - contrasted radiological study of the digestive tract (esophagus, stomach, duodenum, small bowel and colon):

Each twin presented a separate stomach, duodenum, and small bowel, sharing, however, 1 single colon and rectum. The smaller twin presented an imperforate anal canal.

E- Liver and spleen - abdomen ultrasonography (US) and helical CT:

Presence of a fusioned liver with 2 complete and independent hila and 2 gallbladders.

In the bigger twin, the parenchyma drainage was carried out through the hepatic veins to its own IVC, while in the smaller infant, the parenchyma drainage was accomplished by means of venous stems into her sister's IVC, since she did not present an IVC of her own. There was only 1 spleen,



Figure 1 - Thoracoabdominal aortography with identification of the celiac trunk and hepatic, gastroduodenal, and superior mesenteric arteries of the smaller twin

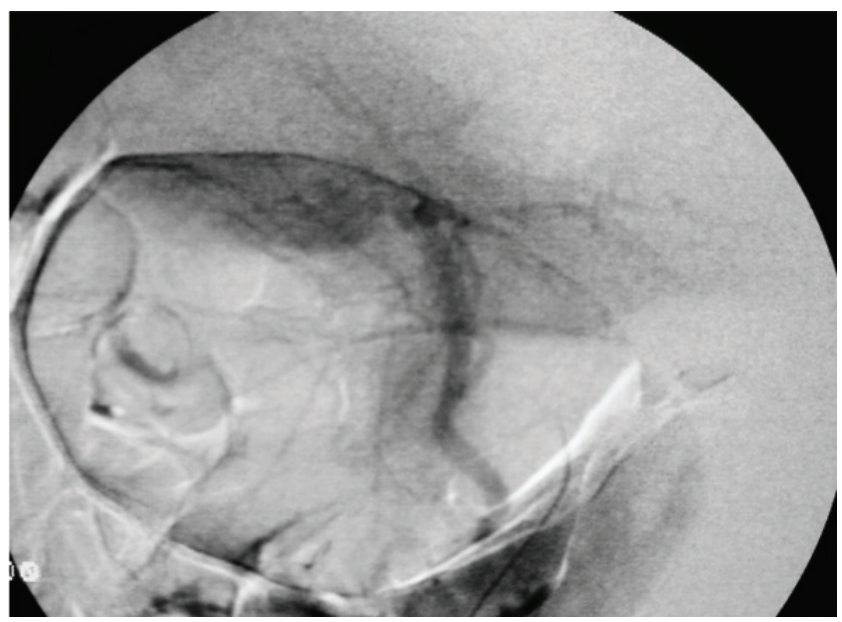

Figure 2 - Venous return phase of the superior mesenteric artery of the smaller twin, displaying the intra-and extra-hepatic portal vein and it belonged to the smaller twin.

Since the hepatic venous draining of the smaller child coursed into the IVC of the bigger twin, their separating operation was contraindicated.

Subsequently, angiographic study was performed under general anesthesia, after the parents had signed an informed consent. The procedure was carried out in the angiography suite through catheterization of the right internal jugular vein and left femoral vein of the smaller infant and through the femoral arteries of both children employing a JB1 catheter $\left(\right.$ Cordis $^{\circledR}$, Johnson and Johnson ${ }^{\circledR}$ ) and hydrophilic guide wire (Terumo 0.032", Boston Scientific ${ }^{\circledR}$ ). Celiac and mesenteric angiographic study (arterial and venous return phase) demonstrated a normal hepatic arterial supply for the smaller twin (Figures 1,2). The study confirmed agenesis of the IVC in the smaller twin, but it also showed in this child that the hepatic parenchyma drained into her own right atrium through small hepatic veins, thus allowing the twins to be successfully separated (Figures 3,4 ).

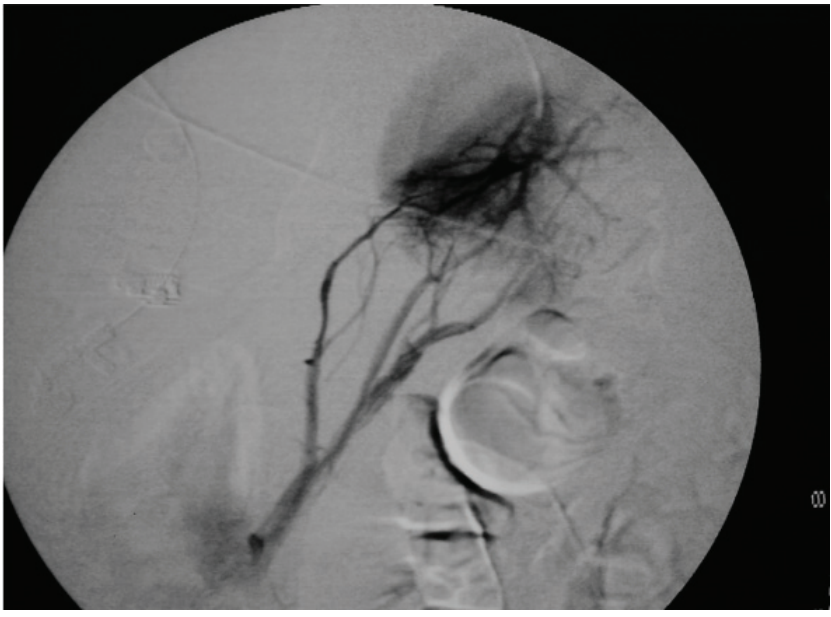

Figure 3 - Selective catheterization through the jugular access of the smaller twin, displaying communication of her hepatic vein with the inferior vena cava of the bigger twin

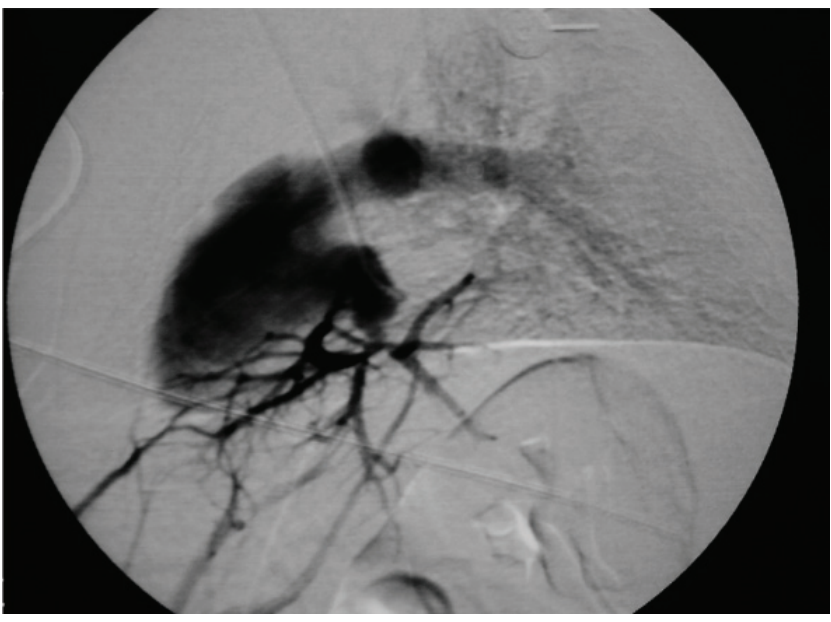

Figure 4 - Hepatic venography of the smaller twin displaying the drainage to her right atrium and posterior opacification of the pulmonary artery 


\section{DISCUSSION}

Conjoined twins are classified according to the most prominent site of conjunction: thorax (thoracopagus); abdomen (onphalopagus); sacrum (pygopagus); pelvis (ischiopagus); skull (cephalopagus), and back (rachipagus). The most common types are: thoracopagus $(73 \%)$ followed by pygopagus (19\%) and finally by ischiopagus $(6 \%) .{ }^{8}, 9$

The phenomenon of conjoined twins with its rare occurrence and the vast diversity of anatomical variation from case to case poses a unique challenge for pediatricians, pediatric surgeons, and radiologists.

The radiological assessment of the different organs for surgical preoperative planning of conjoined twins is of paramount importance. However, the creation of a precise algorithm designed for such evaluation is impractical due to the vast number of anatomical variations existing in such cases.

Great emphasis is given to US and helical CT evaluations in most of the publications, which attribute a secondary position to the other methods of imaging diagnostics, providing only brief and succinct descriptions. However, in this case, due to the inconclusive evaluation possible from the abdominal CT, the option of visceral angiography was adopted to accurately define the hepatic arterial and venous vascular anatomy, allowing the hepatic section without complications.

In this particular case, the initial evaluation by US and helical CT contraindicated the separation surgery of these conjoined twins, since the hepatic parenchyma drainage of one of the twins was not adequately demonstrated.

Thus, detailed angiographic assessment of the twins acquired a fundamental role in the preoperative study, allowing the successful surgical separation of the children.

Therefore, it can asserted that in the preoperative assessment of conjoined twins, no imaging method is superior to another and that the integrated multidisciplinary evaluation for conduct definition is cardinal. Despite being an invasive method, angiographic study should be indicated as a preoperative diagnostic complementation in cases in which the vital anatomic vascular structures are not identified by other means.

\section{REFERENCES}

1. Hanson JW. Incidence of conjoined twinning (letter). Lancet. 1975;2:1257.

2. Spitz L. Conjoined twins. Br J Surg. 1996;83:1028-30.

3. Barth RA, Filly RA, Goldberg JD, Moore P., Silverman NH. Conjoined twins: prenatal diagnosis and assessment of associated malformations. Radiology. 1990;177:201-7.
4. Edmonds LD, Layde PM. Conjoined twins in the United States, 19701977. Teratology. 1982;25:301-8.

5. Zimmermann AA. Embryological and anatomic considerations of conjoined twins. Birth Defects. 1967;3:18-27.

6. Jones KL. Smith's recognizable patterns of human malformation. $2^{\text {nd }}$ ed. Philadelphia, Pa: Saunders; 1988. p. 594-5. 
7. Rudolph AJ, Michaels JP, Nichols BL. Obstetric management of conjoined twins. Birth Defects. 1967;3:28-37.

8. Schnaufer L. Conjoined twins. In: Raffensperger JG, ed. Swenson's Pediatric Surgery. 4th ed. New York: Appleton Century-Crofts; 1980. p. 910-20.
9. Votteler TP. Surgical separation of conjoined twins. AORN J. 1982;35:35-46. 